\title{
Microbiological Assessment of Some Powdered Infant Formulas: From Quality to Antibiotic Resistance Evaluation
}

Toscano $\mathbf{M}^{1}$, Peroni Diego ${ }^{2}$, De Vecchi $E^{3}$, Mattina $\mathbf{R}^{4}$, and Drago $L^{* 1,3}$

${ }^{1}$ Department of Biomedical Sciences for Health, University of Milan, Milan, Italy

${ }^{2}$ Clinica Pediatrica, Università di Verona, Verona

${ }^{3}$ IRCCS Galeazzi Orthopaedic Institute, Milan, Italy

${ }^{4}$ Department of Public Health, Microbiology and Virology, University of Milan, Milan, Italy

\begin{abstract}
Living bacteria are daily used for human consumption as food supplements, also in infant formulas. The amount of ingested viable cells seems to be able to influence the probiotic effectiveness; so it is essential that products available on the market are correctly labelled and that the viability and identity of each strain is ensured. For this purpose, an analysis was conducted on 8 commercial infant formulas to evaluate their stability until the recommended consumption date, the bacterial load and the antibiotic susceptibility of strains used in aforementioned products. Conventional cultural methods were used to isolate and enumerate microorganisms, while their identification was performed by mean of Pyrosequencing. Finally, Minimum Inhibitory Concentrations (MIC) for erythromycin, penicillin, ciprofloxacin and tetracycline were determined using $\mathrm{E}$ test. Most of the tested infant formulas were correctly labelled and the number of viable cells remained stable until the recommended consumption date; however, one product did not contain viable cells of one bacterial species reported in the label. Moreover, all products contained strains showing resistance to at least one antibiotic; resistance to tetracycline and ciprofloxacin was rather common among the tested strains. In conclusion, most of the products analysed in this study were correctly labelled and contained a sufficient amount of bacteria. Although, the antibiotic resistance found in all probiotic strains underlined the need for further investigations about the real safety of probiotic strains used as food supplements.
\end{abstract}

Keywords: Probiotic; Microbiology; Antibiotic resistance

\section{Introduction}

Infant's formulas are the predominant source of nutrition for many infants and are fed during a sensitive period of development, having probably short- and long-term consequences for infant health [1]. In terms of food safety, infants and children are considered to be a part of the high-risk group of individuals, as their immune systems may have not yet be fully developed [2]. Thus, it is reasonable that concerns for safety of products used for infants should be scrutinized closer than foods for adults who have developed several mechanisms to face up with nutrient inadequacies and excess [3]. More recently, several types of bacteria have been increasingly included in Powdered Infant Formula (PIF) or infant food production for their potential health benefits; in literature these bacteria are referred to as probiotic agents [4]. Probiotics are defined as live and vital microorganisms able to benefit human health when consumed in adequate amount, as part of a food or a nutritional supplement [5]. Due to the scarce quality of many commercialized products evidenced by several authors in the recent past [6-8], national guidelines have been developed in different countries to assure high quality standards. Most of them are based on the Joint FAO/WHO Expert Meeting reports on probiotics, which first established in vitro and in vivo properties that should characterize a probiotic microorganism [5].

Probiotic products marketed in Europe should adhere to the Guidelines for Probiotics and Prebiotics for human [9], which is based on the Joint FAO/WHO Expert Meeting reports on probiotics and on the European Food Safety Authority (EFSA) consultations regarding the Qualified Presumption of Safety (QPS) approach. The QPS approach was developed to limit the risk of using potential hazardous microorganisms in the food chain, thus avoiding possible dangerous consequences on human health [10]. The EFSA document also recommends that commercial strains should not harbour transferable antibiotic resistance; in particular determination of Minimum Inhibitory Concentrations (MICs) of the most important antimicrobial for each bacterial strain used in food preparations is strongly recommended by EFSA [10]. Genes conferring resistance to antimicrobials can be transferred in microbial communities by conjugative plasmids, transposons, and integrons, and insertional elements, lytic and temperate bacteriophages. Some studies speculated that also commensal bacteria may act as reservoirs of antibiotic resistance genes which may contribute to the spread of resistance [1113]. The finding that commensal bacteria are able to acquire resistance genes in the intestinal tract [14] and to transfer them to pathogens [15] supports this hypothesis. Antimicrobial agents are commonly used in animal husbandry to cure or prevent the onset of bacterial infections [16]. However, their use at sub-therapeutic doses as growth factors has led over years of use to selection of antibiotic resistant strains within the intestinal microbiota of treated livestock and, as a consequence, antibiotic resistant bacteria have been detected in fermented foods derived from meat and milk [16]. In 1998 a significant percentage of vancomycin-resistant strains of Enterococus were isolated from Danish chicken following the use of avoparcin as feed additive [17]. Conversely,

*Corresponding author: Lorenzo Drago, Department of Biomedical Sciences for Health, University of Milan, Milan, Italy and IRCCS GaleazziOrthopaedic Institute Milan, Italy, Tel: +390266214839; Email: Iorenzo.drago@unimi.it

Received November 07, 2013; Accepted December 23, 2013; Published December 31, 2013

Citation: Toscano M, Diego P, De Vecchi E, Mattina R, Drago L (2013) Microbiological Assessment of Some Powdered Infant Formulas: From Quality to Antibiotic Resistance Evaluation. J Food Process Technol 4: 284. doi:10.4172/21577110.1000284

Copyright: (c) 2013 Toscano M, et al. This is an open-access article distributed under the terms of the Creative Commons Attribution License, which permits unrestricted use, distribution, and reproduction in any medium, provided the original author and source are credited. 
no vancomycin-resistant enterococci were found in Sweden where all antibiotics as food-stimulating feed additives have been forbidden since 1986; accordingly, these results highlighted the pivotal role of antibiotic used as growth factor in the development of antibiotic-resistant bacteria. Moreover, probiotic bacteria used as food supplements are not the only microorganisms involved in the dissemination of resistant determinants in the food chain: a recent study, instead, demonstrated the possible role of ready-to-eat salads in the spread of bacteria within kitchen environment and placing salads within the spectrum of food products that may be vehicles for antibiotic resistant bacteria/genes with clinical interest [18]. Consequently, the safety of food products and, above all the safeness of commercial strains should be evaluated before launch on the market, not only for potential disease-causing traits, but also for their capability of acquiring and transferring resistance determinants [19]. Moreover, guidelines require: i) a minimum labelled concentration of $10^{9} \mathrm{CFU}$ of live microorganisms/ daily dose; ii) identification of each probiotic by integrating phenotypic and genotypic characterization, and conforming of microbial species nomenclature to the international Code of Nomenclature; iii) absence of pathogens. However, several studies demonstrated that the content of some products is not always in agreement with label statements $[7,8]$. The aim of this work was to evaluate if infant formulas available on the market in 2012 were correctly labelled in terms of identity of species or genera and lack of cross contamination by species out of label; also the stability of bacterial counts over time and the antibiotic susceptibility of probiotic strains were analysed.

\section{Materials and Methods}

\section{Products}

A total of 8 commercial infant formulas (each named with a letter from A to $\mathrm{H}$ ) containing live probiotic available on the market in 2012 were included into the study. The majority of products analysed in the present study are Italian, even if some of them are sold abroad.Three products were target for $<6$ months age, while five products were target for $>6$ months age. Three different lots of each product were collected and stored at the controlled temperature indicated on the label, until and during analysis.

\section{Enumeration of microorganisms}

All products were analysed according to ISO 27205:2010 [20] with minor modifications. Powder was weighted and then suspended in 10 $\mathrm{ml}$ of Peptone-salt solution (enzymatic digest of casein $1 \mathrm{~g} / \mathrm{L}$, sodium chloride $8.5 \mathrm{~g} / \mathrm{L}$ ) which was pre-warmed to $45^{\circ} \mathrm{C}$. The suspension was vortexed for 10 seconds and allowed to stand for 5 minutes, shaking occasionally. Serial 10 -fold dilutions were prepared and $100 \mu \mathrm{L}$ of three appropriate dilutions were plated on the following media: De Man Rogosa and Sharpe agar (MRS agar) for lattobacilli; Bifidus Selective medium (BSM) for bifidobacteria; TSA $+5 \%$ blood to check the presence of contaminant organisms. Plates were incubated as follows: MRS agar and TSA $+5 \%$ blood at $37^{\circ} \mathrm{C}$ in $10 \% \mathrm{CO}_{2}$-enriched atmosphere for 48 $\mathrm{h} ; \mathrm{BSM}$ at $37^{\circ} \mathrm{C}$ in anaerobiosis for $72 \mathrm{~h}$. After incubation, the visible colonies were identified, then they were counted and the number of viable microorganisms in each product was expressed as colonyforming units per gram (CFU/gram). The detection limit was $10^{2} \mathrm{CFU} /$ gram. Each package was analysed in duplicate and the mean count of the three lots were calculated. Bacterial loads were assessed when products were purchased and within the recommended period of use of opened package (about 1 month) as stated by manufacturers, to evaluate the product stability over time.

\section{Identification of microorganisms}

Microorganisms were preliminarily identified on the basis of colony morphology [shape, appearance and size] and of Gram staining. Different colonies were picked and purified using the incubation conditions described above. Bacterial colonies were identified by means of PCR as recommended by the Istituto Superiore di Sanità (ISS) [21], or by Pyrosequencing. Bacterial DNA was extracted from pure cultures. Suspensions of about $10^{10} \mathrm{CFU} / \mathrm{ml}$ were heated at $100^{\circ} \mathrm{C}$ for $10 \mathrm{~min}$ and centrifuged at $18,000 \mathrm{x}$ g for $2 \mathrm{~min}$. Supernatants were stored at $-20^{\circ} \mathrm{C}$ until analysis.

The PCR was performed with species-specific primers. Most sequences were taken from the ISS report. Amplification products were analysed by electrophoresis on $1.5 \%$ agarose gel and staining with ethidium bromide.

If PCR was unable to confirm identification of some colonies, the species was identified by sequencing $16 \mathrm{~S}$ rDNA using Pyrosequencing [22]. The sequence of nucleotides [about 50 nucleotides] was then compared to an online database for bacterial identification at species level.

If no viable colonies of a labelled microorganism were isolated, the species-specific PCR was performed by extracting total DNA directly from the product as described for pure cultures.

\section{Antibiotics Susceptibility testing}

Minimum inhibitory concentrations (MIC) for erythromycin, penicillin, ciprofloxacin and tetracycline were determined using $\mathrm{E}$ test (Oxoid, Hants, UK). A 0.5 McFarland bacterial inoculum was prepared and the surface of MRS and BSM plates was flooded with lactobacillus and bifidobacterium suspension, respectively. Subsequently, the surface of the agar was let drying before the strips were applied. Plates were incubated for $24 \mathrm{~h}$ at $37^{\circ} \mathrm{C}$ in $10 \%$ of $\mathrm{CO}_{2}$ enriched atmosphere (lattobacilli) or in anaerobiosis (bifidobacteria). MIC was considered as the lowest concentration at which the border of the elliptical inhibition zone intersected the scale on the strip. Antibiotic susceptibility was evaluated comparing MIC values to breakpoints suggested by EFSA Breakpoints for penicillin were taken from Danielsen and Wind, 2003 and from the Clinical and Laboratory Standards Institute [23].

\section{Results}

\section{Identification and quantification of recovered isolates}

Identification and quantification results are presented in Table 1. All products contained the labelled species and no contamination at the time of purchase was observed. In all products the bacterial counts remained stable until the recommended consumption date on the package. One product out of eight tested (12.5\%) did not contain any viable cells of one of the declared species, although the DNA of the missing species was detected after direct DNA extraction from the product.

\section{Antibiotic susceptibility testing}

A total of 10 strains were isolated from the tested products and assessed for susceptibility to common antimicrobials. Results are summarised in Table 2. All products contained strains showing resistance to at least one antibiotic. Resistance to tetracycline and ciprofloxacin was rather common among the tested strains $(70 \%$ and $60 \%$ of isolated strains, respectively) if compared to that to erythromycin $(10 \%)$ and penicillin $(20 \%)$. Four of the 8 products $(50 \%)$ contained strains showing resistance to at least 2 antibiotics. 


\begin{tabular}{|c|c|c|c|c|c|c|c|}
\hline \multirow[t]{2}{*}{ Product name } & \multirow[t]{2}{*}{ Species claimed on the label } & \multicolumn{4}{|c|}{ Organism detected count (CFU/g) } & \multirow[t]{2}{*}{$\begin{array}{l}\text { Unreported } \\
\text { organism }\end{array}$} & \multirow[t]{2}{*}{$\begin{array}{c}\text { Molecular } \\
\text { identification }\end{array}$} \\
\hline & & TO & 2 weeks & 3 weeks & 1 month & & \\
\hline A & Lactobacillus rhamnosus LGG & $5.2^{*} 10^{8}$ & $5.0^{*} 10^{8}$ & $5.0^{*} 10^{8}$ & $5.0^{*} 10^{8}$ & - & L. rhamnosus LGG \\
\hline B & $\begin{array}{l}\text { Bifidobacterium infantis } \\
\text { Bifidobacterium bifidum } \\
\text { Bifidobacterium breve } \\
\text { Bifidobacterium longum }\end{array}$ & $\begin{array}{l}<10^{2} \\
1.8 * 10^{6} \\
2.0^{*} 10^{6} \\
3.0^{*} 10^{6}\end{array}$ & $\begin{array}{c}<10^{2} \\
1.0^{*} 10^{6} \\
2.0^{*} 10^{6} \\
2.9^{*} 10^{6}\end{array}$ & $\begin{array}{l}<10^{2} \\
1.0^{*} 10^{6} \\
2.0^{*} 10^{6} \\
2.0^{*} 10^{6}\end{array}$ & $\begin{array}{c}<10^{2} \\
1.0^{*} 10^{6} \\
1.0^{*} 10^{6} \\
1.0^{*} 10^{6}\end{array}$ & - & $\begin{array}{l}\text { B. infantis* } \\
\text { B. bifidum } \\
\text { B. breve } \\
\text { B. longum }\end{array}$ \\
\hline C & Lactobacillus reuteri & $6.5^{*} 10^{5}$ & $6.0^{*} 10^{5}$ & $6.0^{*} 10^{5}$ & $5.9^{*} 10^{5}$ & - & L. reuteri \\
\hline $\mathrm{D}$ & Lactobacillus reuteri & $6.3^{*} 10^{6}$ & $6.1 * 10^{6}$ & $6.1 * 10^{6}$ & $6.0^{*} 10^{6}$ & - & L. reuteri \\
\hline$E$ & Bifidobacteriumlactis & $2.0^{*} 10^{7}$ & $2.0^{*} 10^{7}$ & $2.0^{*} 10^{7}$ & $2.0^{*} 10^{7}$ & - & B. lactis \\
\hline $\mathrm{F}$ & Bifidobacterium lactis & $1 . .3^{*} 10^{7}$ & $1 . .3^{*} 10^{7}$ & $1.0^{*} 10^{7}$ & $1.0^{*} 10^{7}$ & - & B. lactis \\
\hline G & Bifidobacterium lactis & $2.5^{*} 10^{7}$ & $2.5^{*} 10^{7}$ & $2.5^{*} 10^{7}$ & $2.5^{*} 10^{7}$ & - & B. lactis \\
\hline $\mathrm{H}$ & Bifidobacterium lactis & $3.1 * 10^{7}$ & $3.1 * 10^{7}$ & $3.0^{*} 10^{7}$ & $2.8 * 10^{7}$ & - & B. lactis \\
\hline
\end{tabular}

* The DNA of the species was found in the product, but no viable colony could be isolated

Table 1: Colony count and identification results.

\begin{tabular}{|c|c|c|c|c|c|}
\hline Product name & Species & Erythromycin & Tetracycline & Penicillin & Ciprofloxacin \\
\hline$A$ & L. rhamnosusGG & $S$ & $S$ & $S$ & $\mathrm{R}$ \\
\hline B & $\begin{array}{l}\text { B. bifidum } \\
\text { B. breve } \\
\text { B. longum }\end{array}$ & $\begin{array}{l}R \\
S \\
S\end{array}$ & $\begin{array}{l}S \\
R \\
S\end{array}$ & $\begin{array}{l}S \\
S \\
S\end{array}$ & $\begin{array}{l}R \\
R \\
R\end{array}$ \\
\hline $\mathrm{C}$ & L. reuteri & $S$ & $\mathrm{R}$ & $\mathrm{R}$ & $\mathrm{R}$ \\
\hline $\mathrm{D}$ & L. reuteri & $\mathrm{S}$ & $\mathrm{R}$ & $\mathrm{R}$ & $\mathrm{R}$ \\
\hline$E$ & B. lactis & $S$ & $\mathrm{R}$ & $S$ & $S$ \\
\hline $\mathrm{F}$ & B. lactis & $S$ & $\mathrm{R}$ & $S$ & $S$ \\
\hline G & B. lactis & $\mathrm{S}$ & $\mathrm{R}$ & $\mathrm{S}$ & $\mathrm{S}$ \\
\hline $\mathrm{H}$ & B. lactis & $S$ & $\mathrm{R}$ & $S$ & $S$ \\
\hline
\end{tabular}

* The DNA of the species was found in the product, but no viable colony could be isolated

Table 2: Susceptibility to antibiotics $(\mathrm{R}=$ resistant, $\mathrm{S}=$ susceptible).

\section{Discussion}

Nowadays, living bacteria are daily used for human consumption; bifidobacteria and Lactic Acid Bacteria (LAB) are often used in the production of fermented foods, beverages and dietary supplements [2426]. The amount of ingested viable cells seems to be able to influence the probiotic effectiveness [27]; so it is essential that products available on the market are correctly labelled and that the viability and identity of each strain is ensured [28].

However, in many countries there are no widely specific regulations concerning the labelling issues and claims that can be made by manufacturers of functional food [29-33]. Moreover, most of infant formulas available on the market did not report the probiotic species used for the product preparation. All products analysed in our study reported only the species contained in the powder, while the bacterial loads were not declared on the label. Most of the tested infant formulas were correctly labelled and the number of viable cells remained stable until the recommended consumption date; however, one product did not contain viable cells of Bifidobacterium infantis as reported in the label. It is known that the drying process strongly affects the viability of microorganisms [34]; bifidobacteria, in particular, are more susceptible to this kind of stress, requiring strict anaerobic condition. Also the packaging and the storage conditions should be carefully evaluated: oxygen, moisture, light and high temperatures may affect the shelf-life of dried products [28].
Furthermore, all products analysed during the study did not contain any bacterial contamination, contrary to what observed by Iversen et al. 2004 [35] who analysed 82 powdered infant formulas and found a contamination by Enterobactersakazakii, Enterobacter cloacae, Klebsiella pneumonia and Citrobacterfreundii, which are often associated with neonatal infections including Necrotizing Enterocolitis(NEC) [35]. As a consequence, the presence of these microorganisms in food supplements should be avoided. Moreover, whereas the minimum recommended daily dose for each product analysed in the present study was about $100 \mathrm{~g}$ of powder, all infant formulas contained an adequate amount of bacteria, as recommended by the Joint FAO/WHO Expert Meeting reports on probiotics [5]. One of the most important selection criteria for bacterial strains intended for use in the food industry is the absence of transferable antibiotic resistance. Several antibiotic resistant bacteria are introduced in human gut through the food chain and potentially, these microorganisms can transfer antibiotic resistance determinants to pathogenic and commensal bacteria located in the intestinal tract. Most probiotics, such as lactobacilli and bifidobacteria, are common members of the human intestinal tract, so the presence of antibiotic resistance in these strains must be systematically screened [36]. Even if the presence of antibiotic resistance might not represent a potential threat when it is present in bifidobacteria cells due to their lack of infectivity, one should considered that bifidobacteria can constitute a reservoir from which resistance genes could be transmitted to pathogenic bacteria. A recent study demonstrated that 
antibiotic resistant bacteria were present even on fresh produce, such as vegetables [37]. That means that also these products can act as source for the dissemination of antibiotic resistance among the intestinal tract [37], probably as a result of plants contamination with antimicrobial resistant bacteria during production following the use of irrigation water contaminated by the environment [38]. For this reason the presence of antibiotic resistance in microorganisms introduced in food chain should be avoided even in non-pathogenic bacteria used in food supplementation [36]. Nevertheless, in this study we observed high frequency of antibiotic resistance among all strains isolated from the tested products. The isolates comprised strains resistant to tetracycline (70\%) and erythromycin (10\%). These data confirmed previous studies in which macrolide resistance was much rare compared to tetracycline resistance in probiotic bacteria [39,40]. Moreover, in the present work we found some penicillin-resistant strains, confirming results from previous studies in which a quite high incidence of penicillin-resistant lattobacilli and bifidobacteria was observed [39,41]. It has been hypothesized that the genetic basis of this kind of resistance is due to either mutations in the penicillin-binding proteins or to the presence of $\beta$-lactamase.

Finally, more than $50 \%$ of tested strains resulted resistant to ciprofloxacin, as demonstrated in a previous work in which susceptibility to ciprofloxacin was variable among lactobacilli and bifidobacteria species used in food supplements $[42,43]$.

In conclusion, most of the infant formula products analysed in this study contained the declared bacterial species in sufficient amount, even if no product label claimed the bacterial load of microorganisms contained. Moreover, specific antibiotic resistance found in all isolated strains is of great concern. This might be the consequence of an extensive use of antimicrobials which has created a selective pressure for point mutations and acquisition of Mobile Genetic Elements (MGE) encoding antimicrobial resistance. One limit of our study was the lack of genetic analysis of antibiotic resistance. Further analyses will aim to investigate the real safety of probiotic microorganisms used in infant formulas and to better understand the mechanisms behind the observed antibiotic resistance, in order to avoid serious health issues for infants and children.

\section{References}

1. Lönnerdal B (2012] Preclinical assessment of infant formula. Annals of Nutrition \& Metabolism 60: 196-199.

2. Abdullah SN, Hartantyo SH, Forsythe SJ (2013) Microbiological assessment and evaluation of rehydration instructions on powdered infant formulas, followup formulas, and infant foods in Malaysia. J Dairy Sci 96: 1-8.

3. Aggett PJ, Agostini C, Goulet O, Hernell O, Koletzko B, et al. (2001) The nutritional and safety assessment of breast milk substitutes and other dietary products for infants: a commentary by the ESPGHAN Committee on Nutrition. J PediatrGastroenterolNutr 32: 256-258.

4. Saavedra JM, Abi HA, Moore N, Yolken RH (2004) Long-term consumption of infant formulas containing live probiotic bacteria: tolerance and safety. Am J ClinNutr 79: 261-267

5. FAO/WHO (2001) Health and nutritional properties of probiotics in food including powder milk with live lactic acid bacteria. Report of a Joint FAO/ WHO Expert Consultation on Evaluation of Health and Nutritional Properties of Probiotics in Food Including Powder Milk with Live Lactic Acid Bacteria.

6. Drago L, Rodighiero V, Celeste T, Rovetto L, VecchiDE (2010) Microbiological evaluation of commercial probiotic products available in the USA in 2009. J Chemother 22: 373-377.

7. Aureli P, Fiore A, Scalfaro C, Casale M, Franciosa G (2010) National survey outcomes on commercial probiotic food supplements in Italy. Int $\mathrm{J}$ Food Microbiol 137: 265-273.
8. Drago L, VecchiDE, Nicola L, Colombo A, Gismondo MR (2004) Microbiological evaluation of commercial probiotic products available in Italy. J Chemother16: 463-467.

9. MinisteroDS(2005) Guidelines for probiotics and prebiotics.

10. EFSA (2008) The maintenance of the list of QPS microorganisms intentionally added to food or feed. Scientific Opinion of the Panel on Biological Hazards. The EFSA Journal 923: 1- 48

11. Perreten V, Schwarz F, Cresta L, Boeglin M, Dasen G, et al. (1997) Antibiotic resistance spread in food.Nature 389: 801-802.

12. Teuber M (2001) Veterinary use and antibiotic resistance. Curr Opin Microbio 4: 493-499.

13. Gevers D, Huys G, Swings J (2003) In vitro conjugal transfer of tetracycline resistance from Lactobacillus isolates to other Gram-positive bacteria.FEMS MicrobiolLett225: 125-130.

14. Mater DD, Langella P, Corthier G, Flores MJ (2008) A probiotic Lactobacillus strain can acquire vancomycin resistance during digestive transit in mice.J MolMicrobiolBiotechnol 14: 123-127.

15. Le TM, Baker S, Le TP, Cao TT, Tran TT, et al. (2009) High prevalence of plasmid-mediated quinolone resistance determinants in commensal members of the Enterobacteriaceae in Ho Chi Minh City, Vietnam.J Med Microbiol 58 1585-1592.

16. Devirgiliis C, Barile S, Perozzi G (2011) Antibiotic resistance determinants in the interplay between food and gut microbiota. Genes Nutr 6: 275-284.

17. Quednau M, Ahrné S, Petersson AC, Molin G (1998) Antibiotic-resistant strains of Enterococcus isolated from Swedish and Danish retailed chicken and pork. J Appl Microbiol 84: 1163-1170.

18. Campos J, Mourão J, Pestana N, Peixe L, Novais C, et al. (2013) Microbiological quality of ready-to-eat salads: An underestimated vehicle of bacteria and clinically relevant antibiotic resistance genes. Int J Food Microbiol 166: 464470

19. Liu C, Zhang Z, Dong K, Yuan JP, Guo XK (2009) Antibiotic resistance of probiotic strains of lactic acid bacteria isolated from marketed foods and drugs. Biomedical and environmental sciences 22: 401-412.

20. ISO and IDF (2010) Fermented milk products-Bacterial starter culturesStandard of identity.

21. Aureli P, Fiore A, Scalfaro C, Franciosa G Metodi (2008) Microbiologic tradizionali e metodi molecolari per l'analisi degli integratori alimentari a base di o con probiotici per uso umano. Rapporti ISTISAN

22. Jonasson J, Olofsson M, Monstein HJ (2002) Classification, identification and subtyping of bacteria based on pyrosequencing and signatura matching of $16 \mathrm{~S}$ rDNA fragments. APMIS 110: 263-272.

23. Clinical and Laboratory Standards Institute (2005) Performance standards for antimicrobial susceptibility testing: fifteenth informational supplement Document M100-S15. Clinical and Laboratory Standards Institute, Wayne, Pa.

24. Caplice E, Fitzgerald GF (1999) Food fermentations: role of microorganisms in food production and preservation. Int J Food Microbiol 50: 131-149.

25. Leroy F, De Vuyst L (2004) Lactic acid bacteria as functional starter cultures for the food fermentation industry. Trends Food Sci 15: 67-78.

26. Wood BJB, Holzapfel WH (1995) The genera of lactic acid bacteria. Black Academic and Professional, London, United Kingdom.

27. Lu L, Walker WA (2001) Pathologic and physiologic interactions of bacteria with the gastrointestinal epithelium. Am J ClinNutr 73: 1124S-1130S

28. Toscano M, VecchiDE, Rodighiero V, Drago L (2013) Microbiological and genetic identification of some probiotics proposed for medical use in 2011 . J Chemother 25: 156-161.

29. Berner LA, O'Donnel JA (198) Functional foods and health claims legislation applications to dairy foods. Int Dairy J 8: 355-362.

30. Przyrembel H (2001) Consideration of possible legislation within existing regulatory frameworks. The American Journal of Clinical Nutrition 73 S471-S475.

31. Huys G, Vancanneyt M, D'Haene K, Vankerckhoven V, Goossens H, et al (2006) Accuracy of commercial bacterial cultures intended for probiotic or nutritional use. Res Microbiol 157: 803-810. 
Citation: Toscano M, Diego P, De Vecchi E, Mattina R, Drago L (2013) Microbiological Assessment of Some Powdered Infant Formulas: From Quality to Antibiotic Resistance Evaluation. J Food Process Technol 4: 284. doi:10.4172/2157-7110.1000284

Page 5 of 5

32. Weese $J(2003)$ Evaluation of deficiencies in labelling of commercial probiotics. Can Vet J 44: 982-983.

33. Elliott E, Teversham K (2004) An evaluation of nine probiotics available in South Africa, August 2003. S Afr Med J 94: 121-124.

34. Morgan CA, Herman N, White PA, Vessey G (2006) Preservation of microorganisms by drying; a review. J Microbiol Meth 66: 183-193.

35. Carol Iversen, Stephen Forsythe (2004) Isolation of Enterobactersakazakii and other Enterobacteriaceae from powdered infant formula milk and related products. Food Microbiology 21: 771-777.

36. Gueimonde M, Sánchez B, de Los Reyes-Gavilán CG, Margolles A (2013) Antibiotic resistance in probiotic bacteria. Front Microbiol 4: 202.

37. Schwaiger K, Helmke K, Hölzel CS, Bauer J (2011) Antibiotic resistance in bacteria isolated from vegetables with regards to the marketing stage (farm vs. supermarket). Int J Food Microbio 148: 191-196.

38. Verraes C, BoxstaelVS, MeervenneVE, CoillieVE, Butaye P, et al. (2013) Antimicrobial resistance in the food chain: a review. Int J Environ Res Public Health 10: 2643-2669.
39. Zarazaga M, Saenz Y, Portillo A, Tenorio C, Ruiz LF, et al. (1999) In vitro activities of ketolide HMR3647, macrolides, and other antibiotics against Lactobacillus, Leuconostoc, and Pediococcusisolates. Antimicrob. Agents Chemother 43: 3039-3041.

40. Temmerman R, Pot B, Huys G, Swings J (2003) Identification and antibiotic susceptibility of bacterial isolates from probiotic products. Int $\mathrm{J}$ Food Microbiol 81: 1-10.

41. Ashraf R, Shah NP (2011) Review Article. Antibiotic resistance of probiotic organisms and safety of probiotic dairy products. International Food Research Journal 18: 837-853.

42. Masco L, Van Hoorde K, De Brandt E, Swings J, Huys G (2006) Antimicrobial susceptibility of Bifidobacterium strains from humans animals and probiotic products. Journal of Antimicrobial Chemotherapy 58: 85-94.

43. Danielsen M, Wind A (2003) Susceptibility of Lactobacillus spp. to antimicrobial agents. Int J Food Microbiol 82: 1-11. 